\title{
Management of acute glaucoma with Pilocarpine-soaked hydrophilic lens
}

\author{
JEFFREY S. HILLMAN \\ Birmingham and Midland Eye Hospital
}

Acute closed-angle glaucoma is an ophthalmological emergency long known as a painful cause of blindness (Banister, I622; Saint-Yves, I 744). Progressive loss of visual field by infarction of nerve fibre bundles at the disc continues as long as the intraocular pressure remains high and its lowering to physiological levels is a matter of urgency. Acute glaucoma usually develops in an eye with an abnormal anatomical configuration, having a shallow anterior chamber with increased curvature of the anterior lens surface (Lowe, I969, 1973). The angle may be blocked by crowding with peripheral iris, by iris bombé consequent upon pupil-block (Mapstone, 1968), by a swollen lens pushing the iris diaphragm forwards, or by a combination of these factors.

The intraocular pressure should first be lowered by medical means to avoid operating upon a congested eye. Traditional treatment involves systemic administration of Acetazolamide and miosis of the pupil with Pilocarpine drops, possibly combined with Eserine. The value of hyper-osmotic agents-intravenous Mannitol, Urea, or Sodium Ascorbate, or oral Glycerol, Isosorbide, or Alcohol-is established (Crews and Davidson, I961), but they may impose a severe strain upon the renal and cardiovascular systems and are usually reserved for patients who have very high intraocular pressure or who have failed response to initial therapy. Treatment with alpha-adrenergic blocking drugs, e.g. Thymoxamine, has been suggested (Rutkowski, Fernández, Galin, and Halasa, I973) but is not widely used.

Pilocarpine is traditionally used at a concentration of 4 per cent. in an "Intensive Pilocarpine" régime involving the administration of one or two drops every minute for 5 min., every $5 \mathrm{~min}$. for half an hour, and then every $15 \mathrm{~min}$. for an hour and a half. These seventeen doses present to the eye approximately 40 to $80 \mathrm{mg}$. Pilocarpine. When the fall in intraocular pressure fails to reach physiological levels this intensive treatment is often continued or repeated. There is uncertainty as to the toxic dose of Pilocarpine on presentation to the eye, but the maximum advised dose on systemic administration is $12 \mathrm{mg}$. (Martindale, 1972).

The administration of Pilocarpine by continuous irrigation through a hard scleral contact lens fitted with inflow and outflow portals has been tried at this hospital. The method is effective but is unsatisfactory because of the overflow of drops onto the face, the immobility of the patient, and the presentation to the eye of a very large dose of Pilocarpine.

A large percentage of the Pilocarpine introduced in drop form into the conjunctival sac is lost via the lacrimal drainage system and only 2 to 3 per cent. penetrates into the aqueous (Harris, I968; Asseff, Weisman, Podos, and Becker, I973). Lerman and Reininger (1971) have shown that if Pilocarpine can be administered in a suitable slow-release form, then a much smaller dose-perhaps io to 25 times less-would be effective. The potential of hydrophilic contact-lens material as a vehicle for drug administration has been appreciated 
for a number of years. Sedláček (1965) used the technique for the application of Homatropine and Mesocaine. Waltman and Kaufman (1970) used Fluorescein as a model drug in rabbit eyes and with a presoaked lens obtained an aqueous concentration four times greater than with frequent drops. They showed that the amount of drug taken up by a lens varies with the material of the lens. North (197I) reported briefly and without details the first use in acute glaucoma in two patients who were cured with a hydrophilic contact lens presoaked in Pilocarpine 4 per cent.

Kaufman, Uotila, Gasset, Wood, and Ellison (1971) showed that a soft lens combined with Pilocarpine I per cent. drops was more effective in lowering intraocular pressure than Pilocarpine 8 per cent. drops alone. Podos, Becker, Asseff, and Hartstein (1972) used hydrophilic lenses after a 2-min. soak in Pilocarpine 0.5 per cent. in ten patients with ocular hypertension and obtained a significant reduction of intraocular pressure. Their studies in vitro showed uptake of Pilocarpine from 0.5 per cent. solution to reach a maximum after soaking for $60 \mathrm{~min}$. and the release rate in vitro and in vivo approximated to a half-life of 30 min. Well over 90 per cent. was gone after $4 \mathrm{hrs}$ of eluting. Assef and others (1973) investigated aqueous levels in monkeys after treatment with a hydrophilic lens presoaked for 2 min. in tritium-labelled Pilocarpine I per cent. Uptake by the 'Bionite' lens was approximately $400 \mu \mathrm{g}$. Pilocarpine and the aqueous levels produced were higher than with frequent drops. Tragakis, Brown, and Pearce (1973) established that long-term wearing of a hydrophilic contact lens does not increase the incidence of culture of pathogenic bacteria from the conjunctival sac.

This study was undertaken to assess the value of a hydrophilic contact lens saturated with Pilocarpine I per cent. in the management of acute closed-angle glaucoma and to compare it with the traditional "Intensive Pilocarpine" régime.

\section{Material and method}

25 eyes with acute closed-angle glaucoma in 22 patients were treated by means of a sterile hydrophilic contact lens which had been presoaked in I per cent. Pilocarpine. Intramuscular Acetazolamide 500 mg. was administered simultaneously. The intraocular pressure was checked by applanation tonometry for $2 \mathrm{hrs}$ and the soft-lens was then discontinued. The results were compared with a retrospective study of 25 randomly selected similar patients treated by the traditional 2-hr "Intensive Pilocarpine 4 per cent." régime together with intramuscular Acetazolamide.

In this study 'Sauflon' hydrophilic contact lenses were used-these are a Vinyl Pyrollidone/ Acrylic copolymer of high water-content. They were $0.2 \mathrm{~mm}$. thick, of diameters 13.50 and $14.00 \mathrm{~mm}$., and of various back central radii ranging from $7 \cdot 80$ to $8.60 \mathrm{~mm}$. They were afocal, being intended originally for use as 'bandage' lenses. On receipt from the manufacturer the lenses were soaked for a minimum of $12 \mathrm{hrs}$ in sterile isotonic saline to remove any monomer residues and then transferred to 25-ml. bottles of preservative-free I per cent. Pilocarpine hydrochloride drops buffered with $0 \cdot$ I per cent. borax to $\mathrm{pH} 6 \cdot 2$. These bottles were sealed and sterilized by autoclaving at $115^{\circ} \mathrm{C}$. for $30 \mathrm{~min}$. The lenses were stored in this sterile form until use and were not used for 3 days to ensure complete equilibration of Pilocarpine between the aqueous solution and the lens. The shelf-life of the preparation is 4 to 8 weeks at room temperature or 4 to 6 months in a domestic refrigerator (Anderson and Fitzgerald, 1967).

No attempt was made at accurate fitting of the contact lenses-the ideal was a flat-fitting very mobile lens, and the lenses of radii 8.20 and $8.60 \mathrm{~mm}$. were most satisfactory. Before applanation tonometry the lens was removed and kept in a sterile gallipot. A single drop of Benoxinate-Fluorescein mixture was instilled into the conjunctival sac for applanation. Before reinsertion of the lens the eye was irrigated with preservative-free isotonic saline ('Minims') to remove all Fluorescein which would otherwise have stained the lens. After use the lenses were sterilized by autoclaving in isotonic saline 
as soon as possible to prevent bacterial or fungal proliferation within the lens causing microscopic degradation of the inner structure. At a convenient later date the lenses were re-autoclaved in Pilocarpine and stored for re-use.

\section{Results}

The lenses were well tolerated by the patients (all of whom had had local anaesthesia of the cornea with Benoxinate for applanation tonometry before treatment). The only exception was one patient who requested removal of the lens after i 5 minutes because of ocular pain. This pain was not relieved by lens removal and instillation of Benoxinate and the cornea showed no staining with Fluorescein, so that his discomfort was probably not attributable to the lens. He was removed from the series. No patients developed corneal staining after 2 hours lens wear and none developed infection in the course of glaucoma surgery following within days of the acute episode. In no case did the lens drop out, despite free mobility of the patient with only a light pad covering the eye under treatment. Figs I and 2 show an eye at the beginning and end of 2 hrs' treatment.

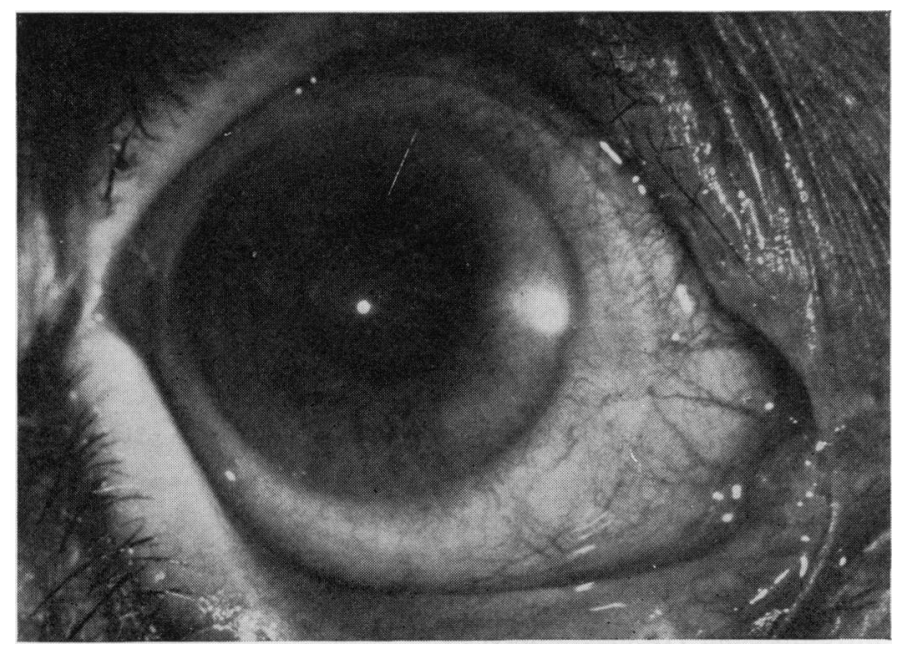

FIG. I Eye with acute closedangle glaucoma at commencement of treatment with hydrophilic contact lens presoaked in Pilocarpine I per cent

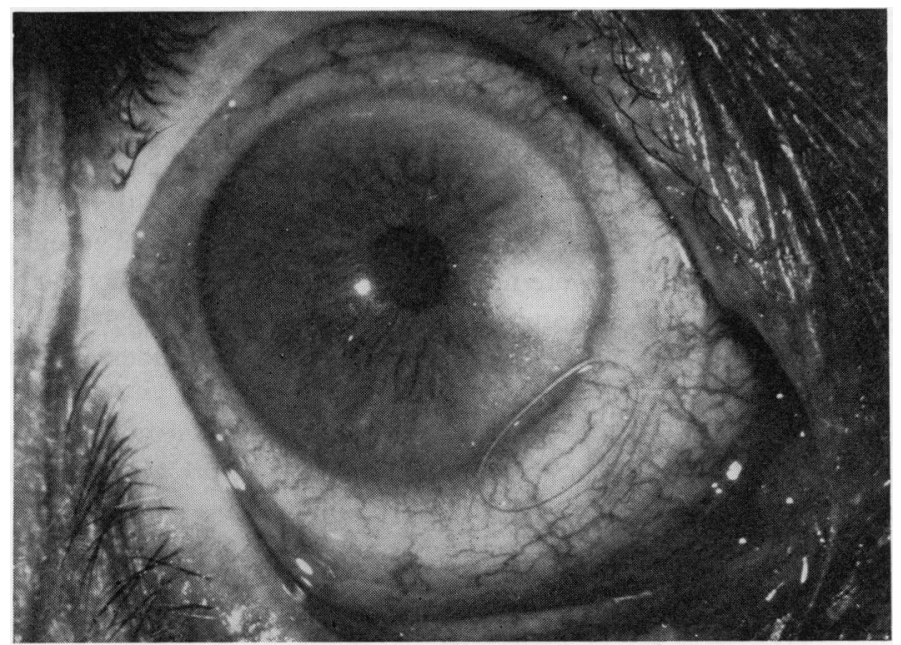

FIG. 2 Same eye as Fig. I after 2 hrs' treatment. The pupil is miosed and intraocular pressure restored to within physiological limits 
The results for the cases treated with presoaked hydrophilic contact lenses are shown in Table I and for the retrospective study of cases treated by "Intensive Pilocarpine" régime in Table II (overleaf).

Table I 25 cases treated by Pilocarpine I per cent. presoaked hydrophilic contact lens and $500 \mathrm{mg}$. Acetazolamide

\begin{tabular}{|c|c|c|c|c|c|}
\hline \multirow{2}{*}{$\begin{array}{l}\text { Case } \\
\text { no. }\end{array}$} & \multicolumn{5}{|c|}{ Intraocular pressure $(\mathrm{mm} . \mathrm{Hg})$} \\
\hline & Initial & After $30 \mathrm{~min}$. & After I $h r$ & After $1 \frac{1}{2} h r s$ & After 2 hrs \\
\hline I & $5^{2}$ & $34(34 \cdot 6 \%)$ & $22(57 \cdot 7 \%)$ & $15(71 \cdot 2 \%)$ & - \\
\hline 2 & 35 & $28(20 \cdot 0 \%)$ & & $15(57 \cdot 1 \%)$ & - \\
\hline 3 & 60 & $12(80.0 \%)$ & - & - & - \\
\hline 4 & 54 & $40(25.9 \%)$ & $36(33.3 \%)$ & & $30(44.4 \%)$ \\
\hline 5 & 60 & $40(33.3 \%)$ & $36(40 \cdot 0 \%)$ & $36(40 \cdot 0 \%)$ & $36(40.0 \%)$ \\
\hline 6 & 70 & $55(21 \cdot 4 \%)$ & $50(28.6 \%)$ & & $4^{2}(40.0 \%)$ \\
\hline 7 & $6_{5}$ & $42(35.4 \%)$ & $34(32 \cdot 3 \%)$ & $34(32 \cdot 3 \%)$ & $34(47 \cdot 7 \%)$ \\
\hline 8 & 50 & $40(20.0 \%)$ & & $32(36 \cdot 0 \%)$ & $14(72 \cdot 0 \%)$ \\
\hline 9 & 48 & $45(6.3 \%)$ & & $35(27 \cdot 1 \%)$ & $20(58 \cdot 3 \%)$ \\
\hline Io & 29 & $24(17.2 \%)$ & & $18(37.9 \%)$ & $20(31 \cdot 0 \%)$ \\
\hline I I & 58 & $22(62 \cdot 1 \%)$ & & $18(69.0 \%)$ & I $6(72 \cdot 4 \%)$ \\
\hline 12 & 64 & $42(34 \cdot 4 \%)$ & & $40(37.5 \%)$ & $32(50.0 \%)$ \\
\hline I3 & $5^{2}$ & $38(26.9 \%)$ & $32(38 \cdot 5 \%)$ & $26(50.0 \%)$ & $18(65.4 \%)$ \\
\hline 14 & 62 & $58(6.5 \%)$ & $50(19.4 \%)$ & $50(19.4 \%)$ & $36(41 \cdot 9 \%)$ \\
\hline 15 & 40 & I6 $(60.0 \%)$ & I0 $(75.0 \%)$ & $10(75.0 \%)$ & - \\
\hline 16 & 60 & & $46(23.3 \%)$ & $40(30 \cdot 0 \%)$ & $32(46 \cdot 7 \%)$ \\
\hline 17 & 72 & & $76\left(\begin{array}{ll}0 & \%\end{array}\right)$ & & $22(69.4 \%)$ \\
\hline 18 & 60 & & $50(16.7 \%)$ & & $40(33.3 \%)$ \\
\hline 19 & 65 & & $55\left({ }^{1} 5.4 \%\right)$ & & $40(38.5 \%)$ \\
\hline 20 & 46 & $36(21 \cdot 7 \%)$ & $30(34.8 \%)$ & $25(45 \cdot 7 \%)$ & $22(52 \cdot 2 \%)$ \\
\hline $2 \mathrm{I}$ & 65 & & $30(53.8 \%)$ & & $20(69.2 \%)$ \\
\hline 22 & 60 & & $35(41 \cdot 7 \%)$ & & $25(58 \cdot 3 \%)$ \\
\hline 23 & $5^{2}$ & & $36(30 \cdot 8 \%)$ & & $32(38.5 \%)$ \\
\hline 24 & 52 & & $20(6 \mathrm{I} \cdot 5 \%)$ & & I $6(69.2 \%)$ \\
\hline 25 & 48 & & $36(25.0 \%)$ & & $25(47.9 \%)$ \\
\hline $\mathrm{Me}$ & & & & & $54^{\cdot 8}$ per cer \\
\hline
\end{tabular}

Intraocular pressures are given in $\mathrm{mm}$. $\mathrm{Hg}$ with percentage fall in brackets. - = discontinuation of lens

The latter group had had applanation tonometry only at the beginning and end of the 2-hr treatment régime, and no information about intraocular pressures after I hr's treatment was available. Fig. 3 (overleaf) shows the mean rate of fall in intraocular pressure for the first fifteen cases treated with presoaked hydrophilic lens. It shows a more rapid fall in intraocular pressure over the first hour than over the second hour. The mean fall for the whole group of $54 \cdot 8$ per cent. in 2 hrs compared favourably with the mean fall of $49 \cdot 7$ per cent. for the "Intensive Pilocarpine" group.

\section{Discussion}

Drugs penetrate hydrophilic contact lenses at a rate which depends upon the pore-size between the cross-linkages of the three-dimensional lattice structure of the lens, upon the 
Table II 25 cases treated by intensive Pilocarpine 4 per cent. drops and $500 \mathrm{mg}$. Acetazolamide

\begin{tabular}{|c|c|c|}
\hline \multirow{2}{*}{$\begin{array}{l}\text { Case } \\
\text { no. }\end{array}$} & \multicolumn{2}{|c|}{ Intraocular pressure } \\
\hline & Initial & After 2 hrs \\
\hline I & 50 & $16(68 \cdot 0 \%)$ \\
\hline 2 & $5^{6}$ & $24(57 \cdot 1 \%)$ \\
\hline 3 & $5^{6}$ & $40(28 \cdot 6 \%)$ \\
\hline 4 & 48 & $34(29 \cdot 2 \%)$ \\
\hline 5 & 54 & $48(11 \cdot 1 \%)$ \\
\hline 6 & 62 & $39(37 \cdot 1 \%)$ \\
\hline 7 & 75 & $26(65 \cdot 3 \%)$ \\
\hline 8 & 75 & $14(8 \mathrm{I} \cdot 3 \%)$ \\
\hline 9 & 50 & $32(36 \cdot 0 \%)$ \\
\hline Io & 60 & $24(60.0 \%)$ \\
\hline II & 42 & $34(19.0 \%)$ \\
\hline 12 & 60 & $22(63.3 \%)$ \\
\hline 13 & 35 & $22(37 \cdot 1 \%)$ \\
\hline 14 & 49 & $23(53 \cdot 1 \%)$ \\
\hline 15 & $4^{I}$ & $28(31 \cdot 7 \%)$ \\
\hline I6 & 60 & $20(66 \cdot 7 \%)$ \\
\hline 17 & 64 & $20(68 \cdot 8 \%)$ \\
\hline 18 & 50 & $28(44.0 \%)$ \\
\hline 19 & 76 & $16(78 \cdot 9 \%)$ \\
\hline 20 & 65 & $45(30 \cdot 8 \%)$ \\
\hline 21 & 40 & $20(50 \cdot 0 \%)$ \\
\hline 22 & 64 & I9 $(70 \cdot 3 \%)$ \\
\hline 23 & $5^{2}$ & $17(67 \cdot 3 \%)$ \\
\hline 24 & 42 & $32(23.8 \%)$ \\
\hline 25 & 60 & $22(63.3 \%)$ \\
\hline Mean & & 49.7 per cent. \\
\hline
\end{tabular}

concentration of drug in the soaking solution and upon the molecular size of the drug. Fluorescein, which enters hydrophilic lenses with great ease, is of molecular weight 332.3 , whilst Pilocarpine hydrochloride is of molecular weight $244{ }^{\circ}$. Some substances, e.g. the

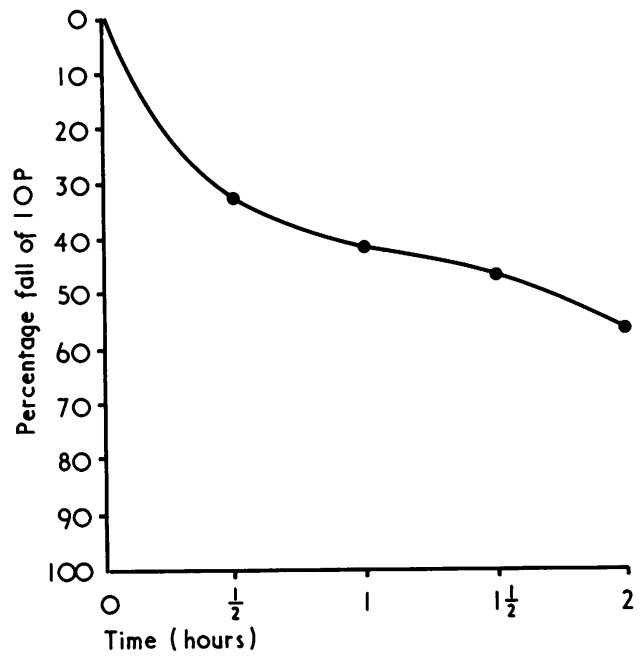

FI 3 Percentage fall in intraocular pressure for the first fifteen cases treated by Pilocarpine I per cent. presoaked hydrophilic lens and $500 \mathrm{mg}$. Acetazolamide

commonly-used preservatives Benzalkonium chloride and Chlorambutanol, have greater affinity for the hydrophilic material than aqueous solution and are concentrated in the lens to levels which are toxic to corneal epithelium.

Most workers on drug delivery by hydrophilic lenses have adopted a technique of a few minutes soak in Pilocarpine immediately before presenting the lens to the eye. The technique described above allows the lens to be prepared at leisure stored in sterile form for use without further preparation.

During a brief 2-min. soak immediately before use, Pilocarpine diffuses in from the soaking solution producing a concentration gradient within the lens-the greatest concentration being at the surface from which the Pilocarpine later diffuses out into the conjunctival sac. A prolonged soak allows equilibration throughout the lens, so that when the Pilocarpine diffuses out from the surface layers it is replenished from the deep part of the lens which acts as a reservoir producing a more sustained high yield. A prolonged soak to a state of equilibrium produces a more standardized form of presoaked lens.

Preliminary biochemical studies at this hospital have shown that approximately 24 hrs' 
soaking is necessary to saturate the Sauflon lens which then holds 4 to $500 \mu \mathrm{g}$. Pilocarpine. Almost all of this is yielded in the first $4 \mathrm{hrs}$ of use (Marsters, I973).

The present clinical study shows that the use of a hydrophilic lens presoaked to saturation in I per cent. Pilocarpine is as effective as an "Intensive Pilocarpine 4 per cent." régime of drops and requires only a fraction of the dose because of the highly-effective slow-release system. In view of the minute dose presented to the eye, the lens may be left in situ for longer than $2 \mathrm{hrs}$ if necessary. The strength of the Pilocarpine in the soaking solution might reasonably be increased and a second trial is in progress using hydrophilic lenses soaked in greater concentration of Pilocarpine. This will be reported when completed. The technique used is less disturbing to the patient than intensive treatment with drops and saves 2 hrs of almost constant nursing attention. Although in the present trial the lenses were inserted and removed by an ophthalmologist, there is no reason why this procedure could not be performed by a nurse after instruction.

\section{Summary}

25 cases of acute closed-angle glaucoma were treated by sterile hydrophilic ("Sauflon") contact lens presoaked in I per cent. Pilocarpine. The method is as effective as intensive medication with 4 per cent. Pilocarpine drops using only a fraction of the dose in a sustained slow-release form. The method of preparation, storage and use of the lenses is described.

I should like to thank Mr. W. Martin Walker and Mr. M. J. Roper-Hall for their advice in the preparation of this paper, the surgeons of the Birmingham and Midland Eye Hospital for permission to treat their patients, Miss M. K. Ridsdale and Mr. A. Broad of the hospital pharmacy for preparing the lenses, and to Dr J. B. Marsters for statistical advice.

\section{References}

Anderson, R. A., and fitzgerald, s. D. (I967) Austr. 7. Pharmacol., 48, Sio8

ASSEFf, C. F., Weisman, P. L., PODOS, s. M., and Becker, B. (I973) Amer. J. Ophthal., 75, 212

BANister, R. (I622) "A Treatise of One Hundred and Thirteene Diseases of the Eyes and Eye-

liddes", 2nd, ed., p. c7. T. Man, London

GREWs, s. J., and DAVIDSON, s. I. (I96r) Brit. 7. Ophthal., 45, 769

HARRIS, J. E. (I g68) In "Symposium on Ocular Therapy", ed. I. H. Leopold, vol. 3, p. 99. Mosby, St. Louis

kaufman, H. E., uotila, M. H., Gasset, A. R., Wood, t. o., and ellison, E. D. (i97I) Trans. Amer. Acad. Ophthal. Otolaryng., 75, 36r

Lerman, s., and Reininger, B. (1971) Canad. 7. Ophthal., 6, I4

LOWE, R. F. (I969) Amer. J. Ophthal., 67, 87

- (1972) Brit. 7. Ophthal., 56, 409

"MARTindale-THE EXTra PHARMAcopoeia" (1972) 26th ed., ed. N. W. Blacow, p. II58.

Pharmaceutical Press, London

MAPSTONe, R. (1968) Brit. 7. Ophthal., 52, 19

MARSTERS, J. B. (I973) Personal communication

NORTh, D. P. (1971) Canad. med. Ass. J., ro5, 561

podos, s. M., BeGKer, B., ASSEFf, c., and hartstein, J. (1972) Amer. 7. Ophthal., 73, 336

rutkowski, P. G., fernández, J. l., galin, m. A., and halasa, A. h. (1973) Trans. Amer. Acad.

Ophthal. Otolaryng., 77, OP 137

SAINT-yVEs, C. DE (I 744) “A New Treatise of the Diseases of the Eyes", 2nd ed., p. 232. T. Osborne,

London

SEDLÁČEK, J. (1965) Čs. Oftal., 21, 509

Tragakis, M. P., Brown, s. I., and PEARCe, D. B. (1973) Amer. J. Ophthal., 75, 496

WAltman, s. R., and KAUfman, H. E. (1970) Invest. Ophthal., 9, 250 